\title{
DIDACTIC TITLES IN LITERATURE: A LOOKAT SELECTED ZAMBIAN-LANGUAGE LITERARY WORKS
}

\author{
Shadreck Kondala \\ University of Zambia \\ shadreckkondala@gmail.com
}

\begin{abstract}
This paper is a descriptive exploration of selected titles of Zambianlanguage literary works that contain in them didactic aspects, that is, forms of general advisory statements and proverbs/sayings as actual titles of the particular books. It demonstrates that the use of proverbial titles makes these works of fiction more concerned with didacticism rather than entertainment. This moralistic disposition which apparently seems to be a trademark of many authors in Zambian languages is a manifestation of the influence of traditional African orature in general and Zambian oral cultures in particular which places emphasis on the teaching of moral values in storytelling. This paper is guided by two literary theoretical approaches namely: the sociological approach which posits that literature should act as a mirror of society as well as to provide solutions for the society; and the ethical approach especially the idea that art should be morally sound.
\end{abstract}

Keywords: Didactic, Didacticism, Prose, Proverb, Moral Lesson, Culture, Traditional

\section{Introduction}

The aim of this paper is to demonstrate the didacticism as reflected in the proverbial titles of Zambian-language literary works. It will focus on prose works although it can be admitted here that other poetic and dramatic works can also exhibit similar trends. In an attempt to impart moral values, authors use well known proverbs and sayings as the titles themselves to achieve that aim. In this regard, one can know the moral of the story just by reading the title which is a proverb. The use of literature to teach morals is a technique that is characteristic of oral literature. The main aim of stories, fables or folktales in an oral society is to teach people morals values that a particular society wishes to promote. Needless to say, Zambia has been largely an oral society especially prior to the coming of the Europeans. Most literary works were oral and these included folktales, fables, myths, legends, proverbs, and other oral genres. Prior to the birth of Zambia, various ethnic groups existed in traditional societies and these were organised according to the respective moral values of that particular society. Such a society strived to instil a particular set of values in their people. These values dictated the type and organisation of the informal curriculum of traditional education. Traditional education was largely achieved in some 
indirect way and this employed storytelling and proverbs, among other things. Proverbs in these societies were used as capsules in which wit and wisdom were stored. One can add here that generally, proverbs still command enormous respect even in modern times. It should be asserted that traditionally, society has always emphasised on the need for moral uprightness for the well-being of its survival and progress. Thus, the onus falls on the elders to transmit knowledge and wisdom and impart it in the younger generations.

Admittedly, informed young people can also be custodians of knowledge and wisdom but generally the greater responsibility falls on the elderly. Being oral societies, emphasis and importance are placed on elders for the inculcation of morals and values to the young people since elders are believed to be custodians of both technical and cultural knowledge, wisdom, experience and generally, cultural information, (Kashoki, 2014; and Lisimba, 1999). The reasoning is that elders have lived relatively and comparatively long and thus, have accumulated numerous valuable experiences from which they draw lessons for the general welfare of the society. Therefore, old age or simply relative elderliness is equivalent to knowledge and wisdom. Elderliness in this sense, as opposed to old age, means that anyone who is older than the other is considered more knowledgeable or wiser than his younger counterpart; thus, the duty falls on this older person to inculcate knowledge and wisdom on the next younger person. Elders have to be respected and their advice should be adhered to. In this light, the elderly are the ones who store/ and possibly formulate proverbs in simple and brief structures to guide the moral conduct of the people in the interest of the welfare of the society, village or kingdom. Thus, by this reasoning, generally, the oldest man or woman in the village is deemed to be the wisest. Of course, there may be few exceptions to this rule as evidenced in proverbs such as 'Amaano yafuma mwifwesa yaya mucuulu' literally as 'knowledge or wisdom moves from the brick and goes into the hill'. This Bemba proverb means that even younger people can inculcate knowledge and wisdom into elderly people.

Moreover, the elderly are the ones with the onus of transmitting folklore and other oral aspects that have been passed on for many generations. They transmit the knowledge of the previous and distant past generations to the current the younger generation. It is expected that the application of this wisdom and knowledge will spur development in terms of cultural, technological, agricultural, social and economic development, of the same society. Proverbs are capsules of such wisdom, (Okpewho, 1984; and Finnegan, 1970).

It is worth pointing out that presently, the practice of various forms of oral literature especially storytelling in most Zambian societies has apparently declined. Suffice to say, that the lifestyles of many Zambians have radically changed both in rural and in urban areas. Indigenous African way of life has largely been replaced or has been largely modified by the western/modern way of life. Orature has declined in the sense that nowadays very few families or communities still gather around the fire or otherwise, in the evening to practice folklore as they used to do in pre-colonial past or the time shortly after Zambia attained independence. This is largely attributed to the advent of the modern way of living. As a result, traditional pastimes have been replaced by modern pastimes; traditional stories 
and games have been replaced by modern ones especially through the use of modern electrical appliances such as televisions, smart phones, stereos, and computers which have replaced the practice of gathering as a family or group to tell stories. One can observe that currently, many people find watching television, listening to the radio, playing on their smart phones or computers preferable to sitting and reserving time for traditional stories, folktales and other oral genres albeit their importance. This trend is especially valid for those in urban areas although rural areas are not an exception.

This, however, should not be taken as a generalisation as one is aware that there are still others who have still stuck to folklore. Moreover, the above comments regarding the decline of oral literature and traditional culture in general vis-à-vis the prominence of modern culture are not meant to demonise modern technological advancement but merely to point out the prevailing trends on the ground. It should be remembered that culture is dynamic and that it is constantly changing. For argument's sake, even the one which is labeled as traditional culture currently, has probably gone through numerous modifications in the past.

Admittedly, oral literature in general has declined; few people are telling folktales. However, proverbs and sayings seem to be an exception. They have largely survived. Where folktales and other oral forms have failed, proverbs have succeeded. This success could be attributed to their general appeal to the minds of many people and also to their brevity. It can be argued that many people in Zambia and elsewhere especially in Southern Africa find proverbs appealing in terms of the supposed wisdom they give, their wit and the beauty of expression. Secondly, because they are brief, they are easy to use and to remember. Proverbs are commonly used both in urban and in rural areas by various people from different age groups especially by the elderly; they embody African values. Nkosi (1981:76) rightly observes that many writers in Africa seem to explore these traditional African values in their works. Hence, contemporary writers have taken advantage of the society's reverence of and fondness for proverbs and subsequently, employed these proverbs as titles for some of their prose works in Zambian languages.

It should be noted that the fact that oral literature has generally declined does not mean that folklore and oral wisdom have perished. Oral literature is still preserved through writing. Other forms still exist in which traditional or folk wisdom is captured through the written medium. Writers with the leaning on, and an interest in the transfer of this wisdom have taken it up to write, transcribe and reinforce such knowledge, wisdom and moral values through the medium of written literary works.

Proverbs have been deployed extensively in the said literary texts in order to teach. They feature both as titles of the books as well as in-text. Didacticism has been the main focus. As mentioned above, the teaching of moral values depends on the stance of the writer whether traditional or modern-oriented. On one hand, writers with a leaning on traditional culture use their works to reinforce various traditional values and customs. On the other hand, modern-oriented writers utilise their works to reinforce the modern values and also encourage people to accept change through their prose works. Both types of 
writers resort to proverbs to achieve their ends. It can be said, however, that most of these Zambian-language literary writers tend to teach morals from the traditional standpoint. Most importantly, proverbs have been used as titles on which moralistic stories are based. This moralistic story is not limited to folktales and fables but includes modern prose works such as novellas and novels with realistic storylines.

The layout of this paper is as follows: after a brief discussion of the nature of didacticism, the paper will then move to the discussion on selected titles in Zambian languages and provide their respective literal meanings. Brief annotated bibliographical information may or may not be provided as this is merely an optional requirement in this article since the researcher has not read the content of all the proverbial titles contained in the article.

\section{Scope}

Although Zambia as a country is blessed with numerous diverse indigenous languages, not all of these languages will be explored in this article. From the linguistic standpoint, there are about between 20 and 26 Zambian languages that represent approximately 72 ethnic groups, (Mambwe, 2014:2). Notwithstanding the above, it is safe to state that the results of the descriptive and exploratory exercise can be generalised to apply to other languages seeing that Zambian Languages are Bantu languages. Bantu languages are similar; Bantu people's cosmology is similar. By extension, indigenous Zambian people are Bantu people (while acknowledging the Khoisan people of course). Suffice to say that Bantu languages are similar; and so are the traditions, practices and beliefs of Bantu people (Mbiti, 2005).

However, only two languages will be used in this article merely to demonstrate the nature of didactic titles as mentioned above. These languages are Bemba and Nyanja. The choice of the two languages is chiefly attributed to the linguistic proficiency of the author. Focus on the two languages does not mean that other languages have been deliberately omitted. However, it is safe to assert that the practice of using didactic titles also obtains in other Zambian languages based on the aforementioned premise regarding the similarity of Bantu languages.

As earlier mentioned, this study is descriptive and exploratory. This article does not attempt to judge whether the practice of didactic titles is good or bad. However, it should be mentioned that the cultural context from which these titles emanate should be appreciated. Telling by the predominance of these proverbial titles on novels, it explains on the importance of the inculcation of morals and values in the respective Zambian indigenous ethnic cultures and various African cultures in general. It shows that most Zambian writers who write in Zambian languages are still placing the emphasis on didacticism and that they largely rely on orality as a source of their inspiration and cultural knowledge.

\section{Theoretical Perspective}

This paper is guided by two literary theories namely, the sociological approach and the ethical approach. The sociological approach posits that literature should act as a mirror 
of society as well as provide solutions for the society, (Dipio, 1998, and Guerin, 2005). Writers of literary works in Zambian languages wish to respond to social problems and, therefore, wish to contribute to the solutions. Some of these problems concern immorality, debauchery, neglect of parents, irresponsibility of young people, and abandonment and neglect of traditional values, among others. In this regard, these writers wish to reinforce morals that will be instrumental in resolving the problems stated above and as a result, resort to the use of proverbs as titles. The use of proverbs as titles is indeed handy since proverbs sufficiently deliver didactic goals on their own although some of them can be enigmatic or hard to understand. In this line, the writers utilise proverbs and sayings in their narratives with realistic characters to reinforce certain moral values in their attempt to attend to certain problems in society. Most people familiar with these proverbs revere them and so can easily accept them as words of wisdom and hopefully adhere to the advice given.

The second theory is the ethical approach. This theory emphasises on the idea that art should be morally sound, (Dipio, 1998 and Guerin, 2005). The ethical approach is hinged on the premise that art should teach. Zambian written literature which is greatly influenced by Zambian oral literature is preoccupied with didacticism. Arguably, the origin of Zambian literary tradition especially in indigenous languages is firmly rooted in and inspired by didacticism as a result of the pervasive influence of orality. In fact, the foundation of publishing of literary works in indigenous languages is linked to education or didacticism. The publishing of literary works from time immemorial in Zambia has been coordinated by a government wing of the Ministry of Education such as NECZAM, Kenneth Kaunda Foundation (KKF) and most recently, Zambia Educational Publishing House (ZEPH) (Chilala, 2014 and 2019). Thus, apart from the idea that writers willingly wanted to teach, the publishing company also required writers to teach certain morals and values to the younger generation through the literary works they produced. Suffice to say, those writers who did not follow the didactic requirements of the publishing company could not have their works published (Chilala, 2019).

Furthermore, teaching more than entertainment is a position that one of the pioneers in Zambian language literary works, Stephen, A. Mpashi, promotes. In his book Ifyo Balemba Amabuuku (1962), he asserts that literature should be concerned with the teaching of morals rather than entertainment. Didacticism should precede entertainment. It should be mentioned that Mpashi and other pioneers of Zambian language literary works must have been influenced by ethical theories as propounded by Plato and Horace.

His book Ifyo Balemba Amabuuku recommends that literature should first teach and then entertain. It is pertinent to highlight that this book served as a guide for Zambian writers and as such, it may have influenced other writers during and after it was published. This was away from the inherent need for traditional members or leaders of society to impart morals in the younger generation for purposes that included national development and unity to say the least.

It is worth noting that these two theories utilised in this article, are somewhat related in that both are intricately societal-oriented. Both are designed to influence society - the 
sociological approach to use literature as a mirror of society and the ethical approach to ensure that writers produce morally sound books for the benefit of society. Besides identifying the ills and problems in society, the sociological theory advocates that writers should make an effort towards solving these problems through the works they produce. On the other hand, the ethical approach explicitly compels the writers to produce morally sound books consciously. On its own, the ethical approach is found wanting in that it advocates a utopian society; an ideal society of moral uprightness devoid of reality. However, this deficiency is eliminated by the sociological approach which brings in realism by presenting literature as a mirror of society. Suffice to say, the blend of these two theories is complementary.

\section{Didactic Titles}

Titles are crucial. The power of titles cannot be underrated. The title alone is capable of giving a hint regarding the contents of the material contained in the book, a novel in this case. As earlier mentioned, the expression 'didactic titles' as used in this article refers exclusively to those titles that teach moral lessons.

As earlier alluded to, didacticism in Zambian language literature is very prominent. This didacticism is manifest in titles themselves. This is a type of literature that places the inculcation of morals to be more important than mere entertainment. These moral titles usually employ proverbs as titles; thus, proverb equals title.

Proverbs serve well in didacticism. Proverbs and sayings are deemed to be the words of wisdom (of course, in the current context, some proverbs have been challenged. For example, ubucende bwa mwaume ... tabutoba ing'anda; Literally meaning: the promiscuity of the man does not break a home and others seem to have been misinterpreted for example, uubomba mwibala... alya mwibala Literally meaning: who works in the garden or field... eats from in the garden or field among others. The former is challenged on grounds that it seems to justify the promiscuity of a married man while the latter is misinterpreted in that it justifies theft and generally, corruption and abuse of office, to say the least).

The point is that wisdom is associated with the elderly hence, the Kongo proverb 'Travelling with an elder is not a pleasant experience but he is the one who knows the route' (Lisimba, 1990:139). This implies that even if young people may argue that they know better, ultimately elders know best. Even if young people can speak of their formal academic qualifications and credentials, their level of wisdom is far below that even the least formally educated elderly man. An equivalent in Bemba is 'Umukulu tapusa kebo, apusa akabwe; literally translated 'an elderly person does not miss their words, they miss a stone.' The actual meaning of the same proverb is that even if an adult may miss hitting a stone or hitting something with a stone, he or she does not miss his or her word of advice. Elderly people are right. There are exceptions of course, in cases where an informed younger person can display tremendous wisdom and possess valuable knowledge.

It should be mentioned that the belief about the wisdom of elderly should be understood in the context of traditional societies and especially oral societies as they existed at that particular time. Hence, the wholesale embrace of the same belief with 
regard to the invincibility of elderly people in terms of wisdom may not hold much water currently, in view of the marked dynamism of culture and life in general. Most modern societies are not organised as they used to be in the past. During that time, wisdom and old age was accompanied with certain duties and responsibilities in the context of traditional society. This does not seem to be the case, although it is in the contemporary society, which is largely meritocratic. Meritocratic societies rely on expertise in specialised fields of knowledge regardless of age. Suffice to say, currently, some elderly people do not seem to assume responsibilities that were once attached to the age and have committed heinous offences, dreadful crimes and scandalous misdemeanors.

Proverbs are widely known by the members of any respective society. Furthermore, they are respected or even revered by many. Thus, when proverbs are deployed as titles, readers easily understand them; they tend to have an idea of what the story will be all about, and are most likely to follow what they advise. (In a case of seemingly contradictory proverbs, context solves the problem). The deployment of the proverb as a title enables the reader to form an idea about the storyline/content of the novel. Clearly, some readers tend to appreciate this practice as it clears away unnecessary suspense but enhances their anticipation about the storyline of the literary work.

Presently, modern society is not purely traditional but it is a blend of traditional and modern. However, for works that were published especially shortly after Zambia's independence, most authors tended to assume a traditional stance on various societal issues. Of course, there were those who embraced modern culture and used their works to challenge traditionalism and traditional conservatists by pointing out various faults in the same and consequently, promoting modern culture. However, generally speaking, various authors firmly embraced a traditional stance and their works were very moralistic besides the fact that many publishing companies compelled them to produce education-oriented titles (Chilala, 2019). It should be mentioned that this practice has not ceased. There are still many contemporary authors who still employ this moralistic approach to literature in their works. Pardon Mwansa's novel Icisalwa Maasaka (2010) can serve as an example here.

Moreover, proverbs have structures (Lisimba, 1990). Some can be very short while others are dual-structured or elliptical structured. An author can opt to use a full proverb or a part of this proverb as a title for the novel. Where the author deploys a first part, the expectation is that the reader will complete the rest. The authors' assumption is that the reader knows the rest of the proverb. Thus, they tend to engage the reader's response actively. For example, Mpashi published a book called Uwakwensha Ubushiku ... (He who escorts you on the journey during the night...). He just used the first part of the proverb in the title. The complete proverb is: Uwakwensha ubushiku, bamutasha ilyo bwaca; literally translated as: 'he who escorts you on a journey at night, is thanked in the morning.' Lisimba (1990: 21) comments that the 'elliptical structure enhances the proverbial message.' 


\section{Demonstration of Didactic Titles}

Here, the titles of books and the respective authors will be listed. In the case of ellipticalstructured proverbs, and the writer only indicates the first part, the second part will be put in brackets. Please note that the demonstration is not conclusive; not all the books in the languages under study have been included as this can require numerous pages. Only a selection of these books has been analysed but these still give a fairly accurate representation of the various books in the said languages and by extension, other Zambian languages.

All the books that will be outlined here have titles that are proverbs or part of proverbs or sayings. Merely from the title, the reader will have an idea regarding the fundamental themes of the novel. As mentioned earlier, the proverbs are usually elliptically-structured; not all of these proverbs are elliptically structured. Others are simply simple statements. In the case of elliptically structured proverbs, on the titles of the covers of the books, it will be noticed that only the first part is indicated. As for the second part, the author seems to assume that the reader will be able to capture it by the very nature of one's competence in the language and the proverbs. In this study, with regard to elliptically-structured proverbs, the part that reflects on the cover of the book will be written in bold print while the second part, the one the author assumes the reader to know, will be indicated in brackets. The titles of the books are arranged alphabetically. To avoid repetition, the complete bibliographical information of these didactic titles will be included in the bibliographical pages at the end of this document.

The presentation is as follow as: (i) the title (ii) the author of the text (iii) the year of publication (iv) the literal translation (v) the storyline or the summary of the main plot. It can be mentioned that the items (i) to (iv) are mandatory in this article while (v) is optional. The annotated bibliographies, storylines or the summary of some of the books will not be provided.

\section{Didactic Titles: Bemba Titles}

1. Akanwa ka Mwefu (takabepa) is a book by S.P. Katongo which was published in 2000. The literal translation of the title is: 'A bearded mouth,' (does not tell lies).

2. Akatanshi Takalisha (Akalekelesha ekalisha) is a book by A. Chimolula which was published in 1956. The literal translation of the title is: 'The first one does not make one to cry' (But the last one makes one cry).

3. Ako Usuulile (Ekopa noko) is a book by E.M. Kabonga published in 1964. The title's literal translation is: 'That which you despise' (is one that comes to marry your mother). This is a story of a poor man who as a result of hardwork later became rich and eventually, managed to get married.

4. Amalibu ya Kuilombela is a book by M.K. Chifwaila published in 1958. The literal translation of the book is: 'Bad consequences that one asked for on his own.' This book is about Bemba mythical narratives and proverbs (Nyongolo, 2014 unpublished UNZA). 
5. Amapinda mulyashi is a book by B.P. Mushindo published in 1958 . The literal translation of the title is: 'Proverbs in conversation.'

6. Bamusha Ulweko is a book by U.G. Chishimba published in 1962. The title's literal translation is: 'He or she is abandoned with nothing.'

7. Icisalwa Maasaka (umwana tasalwa) is a book by Pardon Mwansa published in 2010. The title's literal translation is: 'What is chosen is sorghum,' (A child is not chosen). The story is about an abandoned baby. The couple abandoned a baby who had some physical defect. This baby was later discovered and adopted by a caring couple and he grew up to be a responsible man.

8. Icona-nswa (citula ku mwela) is a book by P.M. Mubanga published in 1992. The literal translation is: 'That which destroys 'nswa' - 'nswa' are edible insects of the termite family. The book gives an account of a love story in which the groom unexpectedly dies just before the anticipated wedding ceremony. The moral of the proverb is that no one can tell when misfortune will befall them.

9. Imamba Taifyala Mamba Mbiye is a book by A.F.C. Musonda published in 2000. The literal translation is: 'The black mamba does not beget another black mamba.'

10. Inshiku Shilabwesha is a book by B. Nkunika published in 1983. The literal translation is: 'Days make someone come back.' It is a story about a beautiful woman who rejected a promising young man but when life became hard and when she was old, she regrets that she had rejected the man who loved her.

11. Musalu wali Pesamba (leelo wabapamulu) is a book P.M. Mubanga published in 1976. The literal translation is: 'The vegetable that was below,' (Is now on top).

12. Nkobekela Tecupo is a book by R.M. Kambole published in 1978. The title's literal translation is: 'Engagement is not marriage.'

13. Nokonkalola Nkaya Nalyo is a book by R.M. Kapindula published in 1973. The literal translation is: 'Wherever I will go bad luck will follow me.' It presents a story of a man with a lot of bad luck.

14. Noushalimo Akabamo is a book by J. Kombe published in 2014. Its literal translation is: 'Even the one who did not take part will be involved.'

15. Ombela umo ombela is a book by S. Chitabanta published in 2009. The literal translation of the title is: 'Do it in a way that you know best.'

16. Pano Calo (tapaba kuwamya) is a novella by S. Mpashi published in 1956. The literal translation of the title is: 'On this World,' (There is no good). The book gives an account of the injustices, cruelty and oppression that many innocent people suffer at the hands of the powerful few.

17. Ubukota Bufuma Nakunuma is a book by M.J. Kalumba published in 1990. Its literal translation is: 'Help comes from behind.'

18. Ukapanya neco Wikete is a book by B. Chibende published in 1955. Its literal translation is: 'You can lose even that which is in your hands.' It is a story about two lovers who could not marry since one of them was not trustworthy. 
19. Ukufunda Umwana (Kuufikapo) is a poetic book by R.M. Kambole published in 1980. The title's literal translation is: 'To teach a child, ' (Don't beat about the bush). The book discusses all the marital rituals and procedures that an initiate should know. The book is quite explicit about topics that many adults would not openly discuss with their children.

20. Ukutangila Tekufika is a book by M.L. Launshi published in 1991. The literal meaning of the title is: 'Being ahead does not mean arriving first at a destination.' This book gives an account of a young lady who refused to marry a young man who loved her simply because this young man failed to pass examinations to Form 3. However, even if he was behind in terms of Grades he continued with school until he completed his O' levels, enrolled at college and successful completed; and finally, found a well-paying job. He ended up with a better position and status in society than the lady and her husband. Then she regretted having dumped him.

21. Ululumbi lwa Mulanda Kukakaata is a book by M.K. Chifwaila published in 1960. Its literal translation is: 'The fame of a poor man is diligence.' This is a story of a young man who was once captured as a slave but later escaped and became king.

22. Uluse Lwalile Nkwale is a book by I. Chipungu published in 1995. Its literal translation is: 'Mercy ate the raven.'

23. Umwana Ashenda (atasha nyina ukunaya) is book by L. Mabuluki published in 1973. Its literal translation is: 'A child who does not travel,' 'Praises his/her mother's cooking of nshima). The story explores the adventurous journey of a young man who travels from Northern Rhodesia to South Africa. The moral of the proverb is that one should travel so that one can understand different ways of living instead of staying at the same spot/area for a long time. Travelling improves one's learning.

24. Uwaingila Mu Mushitu Tomfwa Nswaswa is a book by J.R. Mutale published in 1958. Its literal translation is: 'He who enters the deep shrubs should not be distracted.'

25. Uwakalema Takaleka is a novel by A.R. Chibamba published in 1962. The title's literal translation is: 'One with a fault/disability cannot leave it.'

26. Uwakwensha Ubushiku (bamutasha ilyo bwaca) is a book by S. Mpashi published in 1955. The title's literal translation: 'He/she who escorts you on a journey at night' (You thank him/her in the morning).

27. Uwauma Nafyala (Omina limo) is a novel by S. Mpashi published in 1950. The literal translation is: 'He who beats the paternal aunt/or in-laws' (Beats in full).

\section{Didactic Titles: Nyanja/Chewa}

1. Atambwali Sametana is a book by C.J. Chipinga published in 2002. The literal translation is: 'A crook cannot trick a fellow crook.' 'This book basically talks about two characters Saguza and Paguza who were in the act of tricking each other till they discovered each other and became friends.' (Quoted from Phiri Maiwase's student report-LAL 4510 2014). 
2. Cimaso-maso (Ciletelela) is a book by B. Nkunika published in 2009. The literal translation is: 'Lustful looking here and there' (Is dangerous). It is a story about a womaniser.

3. Coipa Citsata Mwine is a book written by W.H. Murray published in 1968. The literal translation is: 'Bad consequences follow the wrongdoer.'

4. Kunja Kuno Kulibe Wabwino is a book by A.J. Chabwera published in 1967. The literal translation is: 'There is none who is good by external appearance.'

5. Mlandu Suwola is a book by J.G. Banda published in 1986. The literal translation is: 'An offense/crime does not rot.'

6. Mnzako Akapsa Ndebvu (Muzimile) is a book S.A. Mpashi and translated into Nyanja by J.N. Zulu published 1995. The literal translation is: 'When your friend's beard is on fire, '(You should extinguish it for him).

7. Pali Imfa Pali Mabvuto is a book by P.H. Chiwona published in 2017. The literal translation is: 'Where there is death, there are problems.'

8. Samvazanz'ake (anamvwa nkwangwa ili mumutu) is book by F.C. Jere published in 2008. The title's literal translation is: 'He who does not listen to others' (Was axed on the head). This is a story about a troublesome young man.

\section{Conclusion}

The use of proverbs as titles is very predominant among literary works in Zambian languages. The use of proverbs is intended to teach morals to young people or school going children. This type of didacticism is motivated by cultural and national reasons. Acknowledging the fact that Zambian-languages literature is strongly influenced by orality and indigenous cultures, it appears authors feel the need of inculcating morals and values into young people in line with the culture of the respective ethnic group. At national level, through the Ministry of Education and especially government owned publishing houses, authors are influenced to produce didactic literary works in line with the cultural or national values of the country, Zambia. Of course, sometimes certain individual, ethnic and national values are incompatible. However, there is a lot of common ground as to what are deemed as universal acceptable values such as tolerance and co-existence, respect of elders and one another, cooperation, kindness, hardwork, to mention but a few.

Those authors in Zambian-languages literature who tend to transmit cultural norms and values through their works can be said to be moralists. Most of their titles are designed to teach; entertainment is not their primary objective. Moral lessons are dictated by the society, be it at village level or national level, in terms of social, economic, cultural, and political among others. It has to be mentioned that most of these morals as reflected in Zambian-languages literary works so far are based on traditional foundations. As a result, some of the titles and their respective content and implication, fall out of line of modern tradition's values such as gender balance, and equality between the sexes. On the contrary, few authors employ traditional proverbs to teach about modern values of justice, equality and freedom and generally, to counter some of the 'undesirable' practices such as widow 
inheritance and property grabbing in the midst of modern sexually-transmitted infectious diseases, and a contemporary harsh economic system respectively that characterised traditional societies.

It has to be remembered that a lesson of one society may differ from that of another although the revision of proverbs rarely or never happens. Thus, the context in which these moral lessons exist must be taken into account. Authors find proverbs handy because they are 'words of wisdom'. Therefore, for didactic purposes, proverbs are preferred to other forms as they are held to be witty and authoritative. These are approved by the respective society. For the sake of didacticism, authors are not restricted to proverbs exclusively but also employ other well-known statements or sayings in order to achieve their didactic goal.

\section{References}

Banda, J.G.(1986). Mlandu Suwola. Lusaka: Kenneth Kaunda Foundation.

Banda, Mfune, R. (2000). Uwaleta Pabwingi Tonaula; Unpublished Student Narrative Book LAL 432.

Chibamba, A.R. (1962). Uwakalema Takaleka. Lusaka: Kenneth Kaunda Foundation.

Chabwera, A.J.(1967). Kunja Kuno Kulibe Wabwino. Blantyre: Malawi Publications and Literature Bureau.

Chibende, B. (1955). Ukapanya Neco Wikete. Lusaka: Zambia Educational Publishing House.

Chifwaila, M.K. (1958). Amalibu ya Kuilombela. London: University of London Press. .(1960). Ululumbi Lwa Mulanda Kukakaata. London: University of London

\section{Press.}

Chilala, C.H.K. (2019). 'Anglophone Zambian Prose Fiction: Tradition or Transition?' in Hybrid Journal of Literary and Culture Studies 1 (1), (13-29).

.(2014). 'Anatomy of the Challenges Facing Zambian Writers and Publishers of Literary Works' in Journal of Southern African Studies Vol. 40, No. 3 (593-606).

Chimolula, A. (1956). Akatanshi Takalisha. Lusaka: Publications Bureau.

Chipinga, C.C.J. (2002). Atambwali Sametana. Lusaka: Zambia Educational Publishing House.

Chipungu, I.H. (1995). Uluse Lwalile Nkwale. New Edition. Lusaka: Longman Zambia Ltd.

Chishimba, U.G. (1962). Bamusha Ulweko. Lusaka: Kenneth Kaunda Foundation (KKF). Chitabanta, S.(2009). Ombela Umo Ombela. $2^{\text {nd }}$ ed. Lusaka: ZEPH.

Chiwona, P.H. (1989). Pali Imfa Pali Mabvuto. Lusaka: Kenneth Kaunda Foundation (KKF).

Dipio, D. (1998). Theory and Criticism of Literature: LT 201. Kampala: Makerere University. 
Finnegan, R. (1970). Oral Literature in Africa: Nairobi: Oxford University Press.

Guerin, W.L., Labor, E., Morgan, L., Reesman, J.C., and Willingham, J.R.(2005). A Handbook of Critical Approaches to Literature. New Delhi: Oxford University Press. Jere, F.C. (1984). Samvaza'nzake. Lusaka: NECZAM.

Kabonga, E.M. (1964). Ako Usuulile. Lusaka: Rhodesian and Nyasaland Publications Bureau.

Kalumba, M.J.(1990). Ubukota Bufuma na Kunuma. Lusaka: Kenneth Kaunda Foundation. Kambole, R.M. (1978). Nkobekela Tecupo. Lusaka: National Educational Company of Zambia.

Company of Zambia.

Kapindula, R.M. (1973). Nokonkalola Nkaya Nalyo. Lusaka: National Educational Company of Zambia.

Kashoki, E.M. (2014). What on Earth is a Ruling Party in a Multiparty Democracy? Gadsden Publishers: Lusaka.

Katongo,S.P. (2000). Akanwa ka Mwefu. Lusaka: Multimedia Publications.

Kombe, J. (2014). Noushalimo Akabamo. Lusaka: ZEPH.

Launshi, M. (1991). Ukutangila Tekufika. Lusaka: Kenneth Kaunda Foundation.

Mukumbuta, L. (1999). Kongo Proverbs and the Origins of Bantu Wisdom. Libraville: CICIBA.

Mabuluki, L.W. (1973). Umwana Ashenda. Lusaka: Zambia Publications Bureau.

Mambwe, K. (2014). Mobility, Identity and Localisation of Language in Multilingual Contexts of Urban Lusaka. University of Western Cape PhD Thesis Unpublished.

Mbiti, J.S. (2015) African Religions and Philosophy. Nairobi: East African Educational Publishers Ltd.

Murray, W.H. (1968). Coipa Citsata Mwini ndi Mbiri Zina. Lusaka: Church of Central Africa, Presbyterian.

Mpashi, A.S. (1962). Ifyo Balemba Amabuuku. London: Northern Rhodesia and Nyasaland Publication.

. (1950). Uwauma Nafyala. Lusaka: Zambia Publications Bureau; reprint ed., (2009) Lusaka: ZEPH.

. (1978). Mnzako Akapsa Ndebvu (Uwakwensha Ubushiku). Translated by Jacob. N. Zulu. Lusaka: National Educational Company of Zambia (NECZAM); reprint ed., (2012) Lusaka: ZEPH.

. (1956). Pano Calo.

Mubanga, P.M.(1991). Icona Nswa. Lusaka: Kenneth Kaunda Foundation.

. (1976). Musalu Wali Pesamba. Lusaka: National Educational Company of Zambia.

Mushindo, P.B. (1958). Amapinda Mulyashi. Lusaka: NECZAM.

Musonda, A.F.C. (2000). Imamba Taifyala Mamba Mbiye. Lusaka: Grand Design.

Mutale, J.R. (1958). Uwaingila Mu Mushitu Tomfwa Nswaswa. London: University of London Press. 
Mwansa, P. (2010). Icisalwa Maasaka. Lusaka: Maiden Publishing House.

Nkosi, L. (1981). Tasks and Masks. London: Longman Group Limited.

Nkunika, B.S. (2009). Cimaso-maso. Lusaka: Zambia Educational Publishing House. . (1983). Inshiku Shilabwesha. Lusaka: National Educational Company of Zambia.

Nyongolo, E. (2014). Bemba Annotated Bibliography. Unpublished Student report - LAL 4510.

Okpewho, I. (1984). African Oral Literature. Bloomington: Indiana University Press.

Oxford Advanced Learner's Dictionary $8^{\text {th }}$ Edition. 